\title{
Conditions on pronominal marking in the Alor-Pantar languages $^{1}$
}

\author{
SEBASTIAN FEDDEN, ${ }^{a}$ DUNSTAN BROWN, ${ }^{a}$ GREVILLE CORBETT,,${ }^{a}$ GARY \\ HOLTON, ${ }^{b}$ MARIAN KLAMER, ${ }^{\mathrm{c}}$ LAURA C. ROBINSON, ${ }^{\mathrm{b}}$ AND ANTOINETTE \\ SCHAPPER \\ aUniversity of Surrey, ${ }^{\mathrm{b}}$ University of Alaska Fairbanks, 'Leiden University
}

\begin{abstract}
We examine the varying role of conditions on grammatical relation marking (namely animacy and volitionality) by looking at different languages of one family, using both existing descriptions and working with specially prepared video stimuli. This enables us to see the degree of variation permitted within closely related languages. We look at four Alor-Pantar languages (Teiwa, Adang, Kamang, and Abui), Papuan languages of eastern Indonesia. The conditions on argument marking are manifested in different ways. Those languages with syntactic alignment index objects with a prefix, those which have semantic alignment index objects and some subjects with a prefix. In 42 video clips we systematically varied animacy and volitionality values for participants in one and two-participant events. These clips were used in fieldwork to elicit descriptions of the events. The data show that animacy of the object is an important factor which favours indexation of the object on the verb in all four languages to varying degrees. Volitionality, on the other hand, is a factor in the semantically aligned languages only. While the presence of a prefix on the verb is semantically motivated in many instances, marking is not directly determined by verbal or participant semantics, and lexical factors must also play a role.
\end{abstract}

\section{Introduction}

There is a good deal of current research on the marking of grammatical relations, and certain factors have been repeatedly identified as conditions on them. Grammatical relations can operate in relation to the individual arguments of a predicate or be determined by the predicate itself, or a combination of both (Bickel 2010: 411). In order to progress further in this matter we need to understand the possible space of variation in both features related to arguments and those related to the predicate. Here we focus on the former. Typically there are two approaches to investigate this. The first concentrates on examining the different factors with examples from diverse languages, as in Bickel's survey. The second approach is to look in-depth at the changing role of the factors using corpora. Von Heusinger and Kaiser (2011) carried out a detailed examination, applying Tsunoda's (1985) affectedness scale to the 
spread of differential object marking in Spanish. In this paper we take a third approach: we examine the varying role of conditions on grammatical relation marking by looking at these in different languages of one family, using both existing descriptions and working with specially prepared video stimuli. This enables us to see the degree of variation which these factors permit within closely related languages.

In order to examine the role of the different factors we require a family where the conditions are manifested in different ways across the languages. The Alor-Pantar languages constitute such a configuration. They are a family of endangered nonAustronesian languages, spoken on the islands of Alor and Pantar in eastern Indonesia. We introduce these languages in Section 2, but to demonstrate their relevance and interest we give initial examples here. Pronominal marking on verbs appears to be subject to a variety of constraints which differ between languages belonging to different branches of the Alor-Pantar family. In Teiwa, a language from Pantar which has a syntactic alignment system, an object that is indexed by means of a pronominal prefix on the verb is very likely animate. Thus in (1), the verb g-unba' 'meet' has a pronominal prefix, $g(a)$-, which indexes the animate object $n$-oqai 'my child'. 2

(1) Teiwa

Name ha'an n-oqai g-unba'

Sir 2sG 1sG-child 3sG-meet

'Sir, did you see (lit. meet) my child?' (Klamer 2010: 159)

In contrast, in (2) the verb kiri 'pull' has no prefix and the object is inanimate.

(2) Teiwa

bif eqar kopang nuk tei baq kiri

child female small one tree log pull

'A little girl is pulling a log.'

(Response to video clip C18_pull.log_29, SP3)

While objects that are indexed on the verb with a prefix are mostly animate in Teiwa, there are five transitive verbs in Teiwa which appear with a prefix in the corpus, even if the object is inanimate. These are -uyan 'search', -buri 'fix', -laman 'negotiate (a road)', -miar 'play with', and -tane' 'kick'. All of these verbs except the first are rare in the corpus. We can say, however, that it is a typical condition in Teiwa for objects which are indexed on the verb by means of a prefix to be animate.

In contrast with Teiwa, Abui (Alor) has a relatively fluid semantic alignment system in which volitionality of animate referents appears to be an important determinant of pronominal marking on verbs with one argument. In (3) there is no prefix attached to the verb, because the participant has volition for this event.

(3) Abui

na laak

1SG leave

'I go away.' (Kratochvíl 2007: 15)

In (4), on the other hand, the participant is non-volitional in relation to the event, and the verb has a pronominal prefix. 
(4) Abui

no-laak

1SG.II-leave

'I (am forced to) retreat.' (Kratochvíl 2007: 15)

These Abui examples do not involve transitive verbs, but there is a natural connection with the situation in Teiwa. Prefixation in Teiwa is typical of animate objects, and objects are, among other things, expected to be non-volitional (Givón 1985: 90; Malchukov 2005: 79; von Heusinger and Kaiser 2011: 4). It is semantic factors, such as volitionality, which leads Kratochvíl (2007: 177-178, 257) to treat the Abui system as based on actor and undergoer roles (Foley and Van Valin 1984), rather than notions of subject and object, which can more easily be applied to Teiwa.

We concentrate in this paper on animacy and volitionality, but they are not the only factors which have been identified as conditions on pronominal marking in the AlorPantar languages. Table 1 lists all factors that have been identified as playing a role in pronominal marking.

Table 1. Conditions on pronominal marking in the Alor-Pantar languages (based on the existing literature)

\begin{tabular}{|l|l|l|}
\hline Factor & Language & Source \\
\hline Animacy & Teiwa & Klamer (2010: 87-94) \\
\hline Volitionality & Abui & Kratochvíl (2011) \\
\hline \multirow{3}{*}{ Affectedness } & Western Pantar & Holton (2010) \\
\cline { 2 - 3 } & Abui & Kratochvíl (2007: 190-191) \\
\cline { 2 - 3 } & Klon & Baird (2008: 52) \\
\hline Specificity & Abui & Kratochví (2007: 179) \\
\hline Focus & Teiwa & Klamer (2010: 409) \\
\hline Modality & Western Pantar & Holton (2010) \\
\hline
\end{tabular}

Similar factors to those found in constructions involving pronominal prefixes in the Alor-Pantar languages have been reported for differential object marking, including: animacy and definiteness (Bossong 1991; Aissen 2003), specificity (von Heusinger and Kaiser 2005), and affectedness (von Heusinger and Kaiser 2011). Volitionality is, among other things, argued to play a role in differential subject marking in Hindi (Mohanan 1990).

In Section 2 we give an overview of the patterns of pronominal marking in AlorPantar, using representative languages. In Section 3 we discuss our video elicitation method. As we explain in Section 3.1, the video stimuli tests concentrate on animacy, participant number, telicity, volitionality and the contrast between stative and dynamic verbs. Animacy and volitionality are important factors in the constructions under investigation and naturally lend themselves as properties which can be identified by speakers. It was also important to look at properties of the predication (participant number, telicity and the stative-dynamic contrast), because these had been identified as relevant for semantic alignment systems (see Arkadiev 2008: 101) and as important factors in semantic alignment systems in eastern Indonesia (Klamer 2008). We discuss the effects of animacy and volitionality in Section 4 and give our conclusions in Section 5. 


\section{Pronominal marking in the Alor Pantar languages: an overview}

Here we provide a brief overview of the family and the variation in pronominal marking patterns observed in several Alor-Pantar languages. The Alor-Pantar languages constitute a family of at least 20 Papuan/non-Austronesian languages (Holton et al., to appear), spoken on the islands of Alor and Pantar in eastern Indonesia (Map 1).

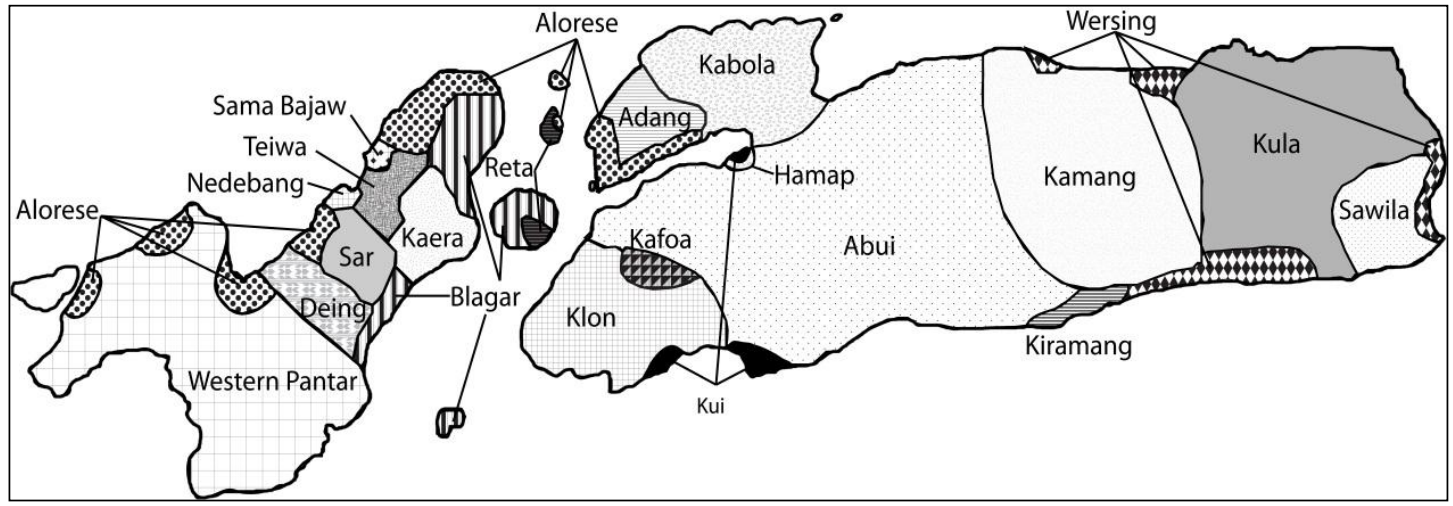

Map 1. The Alor-Pantar languages

The Alor-Pantar languages we will look at in this article are: Teiwa (Pantar), Adang (Straits, West Alor), Abui (Alor) and Kamang (Alor). The genealogical affiliation of selected Alor-Pantar languages is given in Figure 1, based on shared phonological innovations established by Holton et al. (to appear).

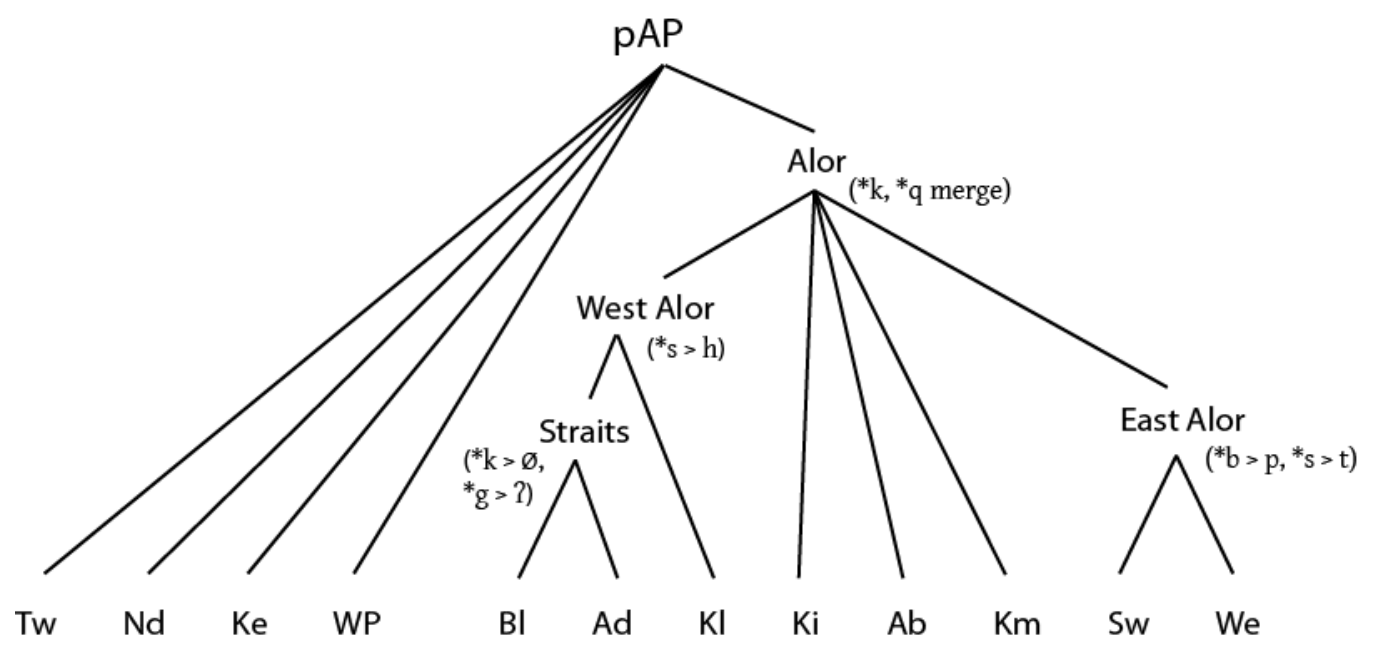

Figure 1. Subgrouping of Alor-Pantar based on shared phonological innovations ${ }^{3}$

The prefixes are all very similar in form, pointing to a common historical origin. ${ }^{4}$ But they have widely different distributions in the individual Alor-Pantar languages so that the lexical verb classes based on the distribution of the prefixes are generally different across the languages. The prefix forms of all four languages can be found in appendix 1 . 
The Alor languages Adang (Western Alor), and Abui and Kamang (both Alor) have more than one series of verb prefixes. Choosing between different prefix series in Abui allows for subtle changes in the semantics of the utterance. The different prefix series in Adang have a more fixed semantics and are much more restricted to occurring with certain verb stems. In addition to multiple prefix series Adang and Abui have a distinction in the third person for each prefix series (see appendix 1), which we call the $\alpha$-type and the $\beta$-type. We have chosen these arbitrary designations because the semantics of these types differ in Adang and Abui. In Adang, the $\alpha$-type prefix indexes the subject of a small number of verbs which can be interpreted as reflexives where the implicit object is coreferential with the subject. The $\beta$-type indexes objects only. This makes Adang similar to Teiwa in that the indexation essentially involves objects. In Abui, on the other hand, the $\alpha$-type prefix indexes an actor, whereas the $\beta$-type prefix indexes an undergoer.

The languages of Pantar that have been investigated, namely Teiwa and also Western Pantar (Holton 2010), each have a single series of prefixes and do not make a distinction between an $\alpha$-type prefix and a $\beta$-type prefix in the third person. Note that whether an Alor-Pantar language has this distinction in the third person cannot be predicted by the number of prefix series: while Adang and Abui each have more than one series, Kamang also does, but lacks the $\alpha$-type vs. $\beta$-type distinction in the third person. The presence of this distinction is also independent of the alignment type of the language: Adang is syntactically aligned, whereas Abui has semantic alignment.

In the discussion of alignment, we use the following primitives for core participants (Dixon 1994): A (subject of a transitive clause), S (subject of an intransitive clause), and $\mathrm{O}$ (object of a transitive clause). The Alor-Pantar languages all have the constituent orders SV and AOV, with OAV being a pragmatically motivated variant in many Alor-Pantar languages.

The prefixes in the Alor-Pantar languages index O's in those languages which have syntactic alignment, and O's and some S's in semantically aligned languages. Teiwa and Adang, subject to the point we have made about its use of the $\alpha$-type prefix, have syntactic alignment. S and A are encoded with a free pronoun, while (animate) O's (as in living humans and animals) are encoded with a prefix. Siewierska's (2011) chapter in the World Atlas of Language Structures indicates that marking of only the object on the verb in this way is rare, occurring in only $7 \%$ of the languages from the sample. Hence, Teiwa and Adang manifest a rare type. Interestingly, as we show below, these two languages exhibit different behaviour with regard to the factors elicited by the video stimuli.

While Teiwa and Adang exhibit syntactic alignment (i.e. always $\mathrm{S}=\mathrm{A}$ ), other AlorPantar languages have systems which could be classified as broadly semantic. Typologically, these fall under active/agentive systems (Mithun 1991) or semantic alignment systems (Donohue and Wichmann 2008). Abui and Kamang display this type of alignment. In such systems, more agent-like arguments of intransitive clauses are coded like agents of transitives, and more patient-like arguments like objects of transitives.

The term "semantic alignment" suggests that the choice of marking is directly determined by verbal or participant semantics. An example of this would be Loma, a South Western Mande language from Liberia (Rude 1983), where alignment is determined strictly by an active/stative distinction in the semantics of the verb. However, it is rare to find languages where the role of semantics is so direct (Arkadiev 2008: 105). More typical is the situation where semantic alignment 
systems, while having some semantic motivation, are still partly determined on lexical grounds (Mithun 2008). Our purpose, therefore, is to determine the role of a controlled set of distinctions across the chosen languages in the realization of pronominal marking of grammatical relations. In the next section we explain how we developed this controlled set of distinctions and how we designed the video elicitation materials.

\section{Methodology}

As our goal is to compare across related languages we are faced with the problem of how to obtain comparable data. The Alor-Pantar languages are described only partly and to varying degrees. Translation-based elicitation brings with it the danger that the responses are heavily biased towards the constructions of the metalanguage, and prompted elicitation using the target language brings with it, among other things, well known difficulties of determining exactly what the consultant is making a judgment about and the extent to which they are trying to accommodate the researcher. We therefore decided to choose video elicitation, as this obviates many of the problems associated with other techniques. While this method entails substantial preparatory work, we can have more confidence in the results.

\subsection{Video stimuli}

This study uses a set of 42 short video elicitation stimuli specifically designed to investigate the impact that various semantic factors have on the patterns of pronominal marking in the Alor-Pantar languages (Fedden et al. n.d.). A list of the clips is provided in appendix 2. The design of an elicitation task consisting of video clips, which systematically vary the parameters under investigation, is inspired by the video elicitation tools developed by the Max Planck Institute for Psycholinguistics in Nijmegen (see Bohnemeyer et al. 2001; Evans et al. 2004).

Given that we are dealing with some systems where there is semantic alignment and others where there is a syntactic alignment system conditioned partly by semantic factors, it makes sense to test the role of conditions which have been identified either for semantic alignment or for their salience in marking grammatical relations such as objects. Animacy is important in Teiwa (Klamer 2010: 171; Klamer and Kratochvíl 2006) and volitionality, telicity, and the stative/active distinction have been identified as major factors in the typological work on semantic alignment systems (Arkadiev 2008). We therefore chose the following five factors, each with two possible values:

a) Number of participants: 1 vs. 2

b) Animacy: Animate vs. Inanimate

c) Volitionality: Volitional vs. Non-volitional

d) Telicity: Telic vs. Atelic ${ }^{5}$

e) Dynamicity: Stative vs. Dynamic ${ }^{6}$

From this, we constructed a possibility space in which we systematically varied the values. The value for 'Animacy' only varies for S or O, i.e. the single argument of 
one-place predicates and for the second argument of two-place predicates. The factor 'Volitionality' varies only with respect to the single argument of one-participant predicates (S) and the first argument of two-participant predicates (A). There are therefore $32\left(2^{5}\right)$ possibilities or cells in the possibility space. Two of these value combinations are logically incompatible, namely the combination of [-Animate] and [+Volitional] and the combination of [+Telic] and [-Dynamic]. As there generally are no volitional inanimates or telic states, we have eliminated these value combinations. This eliminates 7 cases from the one-participant predicates. (There are 4 telic states and 3 additional volitional inanimates. The fourth case with the combination "volitional inanimate" is also a telic state.) For two-participant verbs, only 4 cases have to be eliminated, namely the four telic states. As volitionality and animacy are coded for different participants, a combination of these does not cause a problem.

Telicity and dynamicity have not been identified for the Alor-Pantar languages but we designed the experiment to include these factors because they have been repeatedly recognized as factors which impact on the realization of arguments in semantically aligned languages (see Arkadiev 2008 and references therein).

Although reported to play a role in argument marking in Western Pantar, modality was not included in the experiment. Modality is difficult to test by means of video clips and is only reported to be relevant in a single language (Holton 2010). Focus was not included because it is likewise difficult to test by means of video clips and appears to be relevant only in Teiwa (Klamer 2010: 409). To keep the task manageable we did not include affectedness either. Affectedness is a complex issue (Tsunoda 1985; Beavers 2011) and we believe it is better investigated in a separate study.

The factors definiteness and specificity which are also well-known to have an effect on argument marking (Aissen 2003) were not tested because video elicitation is not the right technique to investigate those. The values of discourse-related factors like definiteness and specificity cannot be systematically varied in any straightforward way in video elicitation.

We tested 21 factor combinations $(32-7-4=21)$. For practical fieldwork purposes, we created a core set of video stimuli for each of the combinations and a peripheral set. Fieldworkers would use the core set as the first task and then the peripheral set where possible. For the languages discussed here both sets were completed. Because there are two sets for each of the 21 combinations, there are 42 clips. For each set the order of the clips was randomized. The order in which the clips were to be shown was fixed after randomization. We tried to find clear examples of a particular value combination where there is a high cognate frequency across the Alor-Pantar languages for the verbs which were likely to be used in the responses. It was also important that stimuli were reasonably easy to film.

\subsection{Speakers and procedure}

The video stimuli were administered to a total of fifteen male native speakers covering a range of five languages. ${ }^{7}$ Our analysis is restricted to those languages for which there were at least three separate speakers. Consequently, we do not discuss Western Pantar. Table 2 provides the basic metadata on these participants. ${ }^{8}$ Note that the Atoitaa and Sama dialects within Kamang are very similar. 
Table 2. Basic metadata for task participants

\begin{tabular}{|c|c|c|c|}
\hline Speaker code & Language & Age & Dialect \\
\hline SP1 & Western Pantar & \multicolumn{2}{|c|}{ Not discussed } \\
\hline SP2 & Teiwa & 31 & Lebang \\
\hline SP3 & Teiwa & 36 & Lebang \\
\hline SP4 & Teiwa & 48 & Lebang \\
\hline SP5 & Adang & 47 & Kokar \\
\hline SP6 & Adang & 37 & Otfai \\
\hline SP7 & Adang & 27 & Tang'ala \\
\hline SP8 & Abui & $\sim 25$ & Takpala \\
\hline SP9 & Abui & $\sim 70$ & Takpala \\
\hline SP10 & Abui & $\sim 60$ & Takpala \\
\hline SP11 & Abui & $\sim 60$ & Takpala \\
\hline SP12 & Kamang & $70+$ & Atoitaa \\
\hline SP13 & Kamang & $\sim 60$ & Sama \\
\hline SP14 & Kamang & $\sim 40$ & Maumang \\
\hline SP15 & Kamang & $\sim 60$ & Sama \\
\hline
\end{tabular}

The video clips were shown to individual participants or groups of participants, one of whom was the primary speaker whose responses were recorded. Elicitation was conducted in Indonesian. Descriptions of the scenes in the clips were elicited using neutral cues, such as Apa yang lihat? 'What did you see?' or Apa yang terjadi? 'What happened?'. If the initial description didn't include a verb which roughly corresponded to the English verb in the clip label, the field experimenters probed for the intended verb in a minimal way. All sessions were audio-recorded and the responses transcribed.

Responses that we counted as valid had to conform to the specific factor combination for which they were given as a description. For example, the description of the clip "hear person" had to involve an animate entity as the object, e.g. "hear the man". So responses involving a body part, such as "he hears the man's voice" were not counted for the relevant feature combination. Tables giving the proportion of prefixed verbs measured against the total of valid responses for a certain factor or combination of factors will be used in this paper to show the effect of animacy or volitionality on prefixation. Figures are given for individual speakers as well as aggregated data for all speakers of each language. All percentages are conventionally rounded to yield whole numbers.

\section{Argument properties}

In this section we consider the factors which can most readily be associated with the verb's arguments, namely animacy and volitionality. The former is a property which can be used to more or less exhaustively categorize nominals, whereas the latter has a greater relationship with events, in that being volitional is often an observable property from the specific context. The other two factors we tested for, telicity and dynamicity, are more closely related to events and therefore are not discussed further in this paper. Our tasks showed however that there is potentially an effect of telicity in the two semantically aligned languages Abui and Kamang in that the telicity factor 
patterns according to the number of arguments. We give some numbers for telicity in appendix 3. Whether a verb was stative or dynamic had no effect on the indexation patterns.

We consider now in detail the effects of animacy and volitionality in Teiwa, Adang, Kamang, and Abui.

\subsection{Animacy in Teiwa}

Animacy is an important factor in Teiwa. O's which are indexed on the verb by means of a prefix are almost always animate. In the responses in our experiment, for an object of a transitive verb to be indexed with a prefix it even appears to be a necessary condition that it has an animate referent but we know from the Teiwa corpus that there are some very rare cases of inanimate O's which are indexed on the verb.

In the experiment, all three Teiwa participants used prefixes exclusively with animate objects of transitive verbs. More importantly, they consistently used prefixes for the same three verbs, all of which are transitive and have animate objects. These are -tan (tup) [lit. call get.up] 'wake someone up', - $u$ 'an 'hold someone in one's arms', and -arar 'be afraid of someone'. These are illustrated in (5), (6), and (7):

(5) Teiwa

kri nuk ma bif goqai ga-tan-an tup

old.man one come child 3SG-call-REAL get.up

'An old man comes and wakes up a small child.'

(Response to video clip P07_wake.up.person_19, SP4)

(6) Teiwa

kri nuk bif goqai eqar g-u'an-an taas

old.man one child female 3sG-carry-REAL stand

'An old man is standing carrying a small girl.'

(Response to video clip P15_hold.person_24, SP4)

(7) Teiwa

bif goqai eqar daam ga-arar

child female snake 3sG-be.afraid.of

'The girl is afraid of the snake.'

(Response to video clip C08_be.afraid.of.snake_35, SP4)

Having an animate object is not a sufficient condition for the object to be indexed by a prefix. In our experiment, many animate objects were not indexed with a prefix. In fact, indexation of an animate object in Teiwa accounts for $50 \%$ of the instances, as in Table 3.

Table 3. Prefixation with animate O's in Teiwa

\begin{tabular}{|l|r|r|r|c|}
\hline & SP2 & SP3 & SP4 & All \\
\hline Animate O's & 5 & 6 & 7 & 18 \\
\hline Prefix & 3 & 3 & 3 & 9 \\
\hline Proportion & $60 \%$ & $50 \%$ & $43 \%$ & $50 \%$ \\
\hline
\end{tabular}


The results suggest that the animacy of the object cannot be the whole story. It is therefore worth considering whether (a) the rule of object indexation is at all productive in Teiwa and if so, whether (b) the effects we have observed in relation to a property of the argument might more readily be associated with the verb itself.

To address the first question we did a corpus search for Teiwa inspired by the quantitative method in Baayen (1992) and subsequent work based on that. The Teiwa corpus we used for this consists of about 16,900 words of which roughly one third is elicited material. The assumption is that if a morphological process is productive in a language hapax legomena in the corpus will exhibit it. The basic intuition behind this is that lower frequency items will need to rely on the creativity associated with rules, whereas memory will have a greater role in relation to high frequency items. Therefore, if in Teiwa most instances of transitive verbs with animate objects which occur only once have a prefix, then the rule can be considered productive. If, on the other hand, there is no difference in the behaviour of the hapax legomena, i.e. if there is a more or less even split, then it is impossible to conclude anything.

The results for transitive verb hapaxes are summarized in Table 4. The number before the slash includes hapaxes in elicited material, the number after the slash excluded elicited items.

Table 4. Hapax legomena of transitive verbs in Teiwa

\begin{tabular}{|l|l|l|l|}
\hline & $\begin{array}{l}\text { Total number } \\
\text { of hapaxes }\end{array}$ & With prefix & Proportion \\
\hline With animate object & $9 / 7$ & $8 / 6$ & $88.8 \% / 85.7 \%$ \\
\hline With inanimate object & $13 / 12$ & $1 / 1$ & $7.7 \% / 8.3 \%$ \\
\hline
\end{tabular}

Bear in mind that we did not search for all verb hapaxes, only transitive ones. The number of intransitive verb hapaxes is irrelevant to the question whether morphological rules in transitive verbs are productive, as intransitive verbs are not prefixed in Teiwa at all.

These results strongly indicate that prefixation of animate objects is indeed productive in Teiwa and not an artefact associated with high frequency. $88.8 \%$ of transitive verb hapaxes with an animate object actually also have a prefix. If the elicited hapaxes ( 2 in total) are eliminated, the proportion is still $85.7 \%$. Conversely, if we look at transitive verbs with an inanimate object, only about $8 \%$ of the hapaxes have prefixes. Of course, the Teiwa corpus is nowhere nearly as massive as the ones Baayen used, but they give us the best evidence we can obtain at the moment.

Having established that object indexation seems to be a productive rule in Teiwa we turn to the second question, namely whether the observed animacy effects might be associated with the verb itself. Given the possibility of prefixation or its absence, there are two main classes of transitive verb which can be found in Teiwa.

One class of transitive verbs index the object with a prefix on the verb, and given the correlation with animacy, the objects have animate referents. Furthermore, a separate animate noun phrase constituent co-referent with the prefix may optionally be present. In addition to the transitive verbs -arar 'be afraid of', -tan (tup) [lit. call get.up] 'wake up', and -u'an 'carry', further examples from the corpus are: -ayas 'throw at', -bun 'answer', -fin 'catch', -lal 'show to', -liin 'invite', -pak 'call', -panaat 'send to', -regan 'ask', -rian 'look after', -sas 'feed', -soi 'order', -tiar 'chase', -ua' 'hit', - 'uam 'teach', and -wei 'bathe'. 
A second class of transitive verbs has no prefix. They can be accompanied by a separate noun phrase for the inanimate object. Examples from the experiment are: $s i$ ' 'wash', miman 'smell', and wuraq 'hear'. Further examples from the corpus are: bali 'see', bangan 'ask for', boqai 'cut up', dumar 'push away', hela 'pull', mat 'take', me' 'be in', moxod 'drop', ol 'buy', pin 'hold', qas 'split', taxar 'cut in two', tian 'carry on head or shoulder'.

Given the association between prefixation and the value for animacy, these two groups constitute the largest classes for transitive verbs. However, if prefixation was purely a matter of sensitivity to the animacy property of the argument, rather than a manifestation of the class to which a verb belongs, we would expect one and the same verb to alternate between prefixation and non-prefixation, depending on the animacy of the object it happened to be taking. But the number of transitive verbs that show prefix alternation is low in Teiwa. By prefix alternation we mean one of two things. Either, that a verb has a prefix and an animate object or no prefix and an inanimate object. Or, that a verb selects one prefix series with animate objects and another prefix series with inanimate objects. We consider each of these two possibilities in turn. None of these contrasts were elicitated through the video task; the following description is from Klamer (2010).

First, a class of five verbs alternates between having a prefix and an animate object or having no prefix and an inanimate object. These are -dee 'burn someone' and dee 'burn something', -mai 'keep for someone' and mai 'save something', -mar 'follow someone' and mar 'take/get something', -mian 'give to someone' and mian 'place at some location', -sii 'bite someone' and sii 'bite (into) something'. Note that the animacy of the object sometimes also involves a semantic change. An example is given in (8) and (9):

(8) Teiwa

na ga'an mar

1SG 3SG take

'I take/get it' (Klamer 2010: 91)

(9) Teiwa

na ga-mar

1SG 3SG-follow

'I follow him/her' (*‘I take him/her’) (Klamer 2010: 91)

Second, there is a class of four transitive verbs that select an animate or inanimate object, and encode either of them with a verbal prefix. Inanimate objects are indexed with the canonical prefix. Animate objects take an augmented form (with a glottal stop). This distinction pertains to the third person only because first and second person referents are intrinsically animate. This class comprises only: -wulul 'tell someone, tell something', -wultag 'talk to someone, talk about something', -kiid 'cry for someone, cry about something', and -tad 'strike someone, strike at something'. A minimally contrastive sentence pair is given in (10) and (11):

(10) Teiwa

ha gi ga'-wulul

2SG go 3SG.AN-talk

'You go tell him. / You go talk with him.' (Klamer 2010: 92) 
(11) Teiwa

ha gi ga-wulul

2SG go 3SG-talk

'You go tell it (i.e. some proposition)!' (Klamer 2010: 92)

It is our view that this small class of transitive verbs which require different prefixes to index animate and inanimate objects is particularly important for our understanding of the role of animacy in Teiwa. What this indicates is that there is a small inflectional paradigm for verbs in which the animate-inanimate distinction constitutes a feature realized by different prefix types. In this one morphological class the distinction is realized by two contrastive forms, whereas in the small class where there is alternation, the distinction is realized by the contrast between a prefix and its absence, as for example in the pair -dee 'burn someone' and dee 'burn something'. Verbal classification is therefore relevant in at least two respects. First, Teiwa transitive verbs tend to be restricted in terms of the object types they take, so that the same verb rarely contrasts between having an animate object and an inanimate one. Second, when this distinction is possible in the two smaller classes of verbs the animacy distinction is potentially inflectional.

This realization of the animate-inanimate distinction is not absolute, however. In the video elicitation task, the verbs with prefix -tan (tup) [lit. call get.up] 'wake up', $-u$ 'an 'hold in one's arms', and -arar 'be afraid of', were only used with animate objects. They were not used in descriptions of events which involve an inanimate object. The corpus, however, shows a few transitive verbs which can (or have to) have an inanimate object indexed with a prefix. The verbs -uyan 'search', -buri 'fix', -laman 'negotiate (a road)', -miar 'play with', and -tane' 'kick' appear with a prefix in the corpus, even if the object is inanimate. To the best of our knowledge, in the corpus, - uyan occurs with animate objects as well, the others only occur with a single inanimate object each. The verb -laman 'negotiate' occurs with the object 'road', -miar 'play with' with 'embers', and -tane' 'kick' with 'coconut'.

Compare -uyan with an animate object (12) and an inanimate object (13):

(12) Teiwa

a qavif ga-uyan gi si $\quad$...

3SG goat 3sG-search go SIM

'He went searching for [a] goat...' (Klamer 2010: 88)

(13) Teiwa

ha gi ya' siis nuk ga-uyan pin aria'

2SG go small.bamboo.sp. dry one 3SG-search hold arrive

'[...] you go look for dry bamboo to bring here' (Klamer 2010: 340)

The converse situation where a Teiwa verb takes no prefix but has an animate object is well attested in the responses to the video elicitation task. The verbs oqan 'hug', wavar 'lean on', tumah 'bump into', and kiri 'pull' never have a prefix, yet occur with either an inanimate or an animate object. For example, tumah 'bump' occurs with an inanimate object in (14), which we would expect given the absence of the prefix, but it can also take an animate object (15): 
(14) Teiwa

kri nuk tewar wa tei tumah

old.man one walk go tree bump

'An old man walks and bumps (into) a tree.'

(Response to video clip C16_bump.into.tree_42, SP4)

(15) Teiwa

uy masar nuk wa kri tumah

person male one go old.man bump

'A man is going and bumps (into) an old man.'

(Response to video clip C13_bump.into.person_38, SP4)

Other transitive verbs from the corpus which are never prefixed but allow an animate object are bali 'see, watch', mat 'take', ga 'take along', and moxod 'drop'. In a certain sense, verbs which occur with both object types and always use the prefix, or occur with both object types and never use it, can be interpreted in the same way: they have no paradigmatic distinction between animates and inanimates. In some of the other Alor-Pantar languages, this distinction is more prominent because of the larger repertory of prefixes. But the crucial point is that the distinction is best understood as a partial inflectional property of the verb, and one which has different morphological reflexes according to verb class. The property is partial, because the majority of verbs cannot take both animate and inanimate objects.

To sum up, animacy is an important factor in Teiwa, where almost all $\mathrm{O}$ arguments which are indexed with a prefix are animate. Being an animate $\mathrm{O}$ is not a sufficient condition for an argument to be indexed in Teiwa. Many animate O's are not indexed and the number of verbs which alternate between having an animate $O$, which is indexed with a prefix, or having an inanimate object, which is not indexed or indexed with a different prefix, is quite small.

\subsection{Animacy in Adang}

Adang verbs which take prefixes are a closed and arbitrary class (Haan 2001: 237), which indexes its object with a prefix regardless of any properties of the arguments. Here, we will show that this is essentially correct, but that animacy has some effect because the proportion of animate O's which are indexed is greater than half.

Like Teiwa, Adang has syntactic alignment and prefixal marking on the verb is basically restricted to indexing O's. Compare an intransitive clause (16) and a transitive clause (17). All Adang examples are given using the orthography employed by Haan (2001).

(16) Adang

bel $\min$

dog die

'Dogs die.' (Haan 2001: 212) 
(17) Adang

bel n-eh

dog 1SG.I-bite

'A dog bit me.' (Haan 2001: 230)

Looking at the responses for Adang in Table 5, it is obvious that many more prefixes were used than in Teiwa. The responses for Adang show that verb prefixes are almost exclusively used in transitive clauses. This is of course because Adang has syntactic alignment.

Table 5. Total Adang responses for one- and two-participant events (responses to the video stimuli)

\begin{tabular}{|l|r|r|r|r|}
\hline & SP5 & SP6 & SP7 & All \\
\hline One-participant events & 16 & 15 & 16 & 47 \\
\hline With prefix & 1 & 1 & 1 & 3 \\
\hline Proportion & $6 \%$ & $7 \%$ & $6 \%$ & $6 \%$ \\
\hline & & & & \\
\hline Two-participant events & 14 & 10 & 11 & 35 \\
\hline With prefix & 9 & 5 & 5 & 19 \\
\hline Proportion & $64 \%$ & $50 \%$ & $45 \%$ & $54 \%$ \\
\hline
\end{tabular}

Each speaker used one prefixed form for a one-participant event. All of these involved the $\alpha$-type prefix $s a$ - (see Adang prefixes in the appendix 1, Table C). ${ }^{9}$ This type of prefix is always co-referential with the subject of an intransitive clause. An example from the video elicitation task is (18):

(18) Adang

'ai lote nu sameng $u=a b$ mih-eh sa-tel toh lame child male one wall OBL=lean sit-PROG 3.I-lift stand walk 'A boy is sitting leaning on a wall, he gets up and walks.' [ $\alpha$-type prefix: $s a$-] (Response to video clip P21_stand.up_02, SP6)

For two-participant events Adang speakers used prefixes for all responses where Teiwa speakers used prefixes. The Adang verbs in question are -hou toh [lit. call get.up] 'wake up', -foh 'hold in one's arms', and -baroc 'be afraid of'. For twoparticipant events the $\beta$-type prefix is used to index the $O$ of the transitive verb, while the $\mathrm{A}$ is never indexed. Examples illustrating prefixation with the three verbs in question are given in (19), (20), and (21):

(19) Adang

'ai tumo so-'ai 'a-hou toh

old.man 3.II.POSS-child 3.I-suggest stand

'The old man wakes up his child.' [ $\beta$-type prefix: ' $a$-]

(Response to video clip P07_wake.up.person_19, SP5) 
(20) Adang

sa so-'ai 'a-foh-eh

3SG 3.II.POSS-child 3.I-carry-PROG

'He is carrying his daughter.' [ $\beta$-type prefix: ' $a$-]

(Response to video clip P15_hold.person_24, SP5)

(21) Adang

'ai 'sb mon 'el-baroc

child woman snake 3.IV-be.afraid.of

'The girl is afraid of the snake.' [ $\beta$-type prefix: 'el -]

(Response to video clip C08_be.afraid.of.snake_35, SP5)

In addition to these three verbs all of which have animate O's, prefixes indexing animate O's were also used for the serialization $t \varepsilon^{\prime} \varepsilon n g$ ( $h s^{\prime}$ ) -lap [run (come) -look.for] 'run to'. The verbs $-d \varepsilon$ 'eat' and $-f a$ ' 'hug' were always used with a prefix but invariably had inanimate O's and -bi'ing 'pull' occurred with either an animate or an inanimate $\mathrm{O}$, yet always had a prefix. The verb - $n$ ' ' 'cause' was used by SP5 in a causative construction with bokang tar 'lie bokang' for P08_bend.person_36 and with palel 'bent' for P14_bend.plank_39.

In the context of our experiment, it seems that animacy has good predictive value for the prefixation of an Adang verb. Adang and Teiwa both have syntactic alignment but animacy was a necessary condition for the presence of a prefix in Teiwa, while this is not the case for Adang (Table 6).

Table 6. Proportion of transitive prefixed verbs with animate objects in Adang for all three speakers (responses to the video stimuli)

\begin{tabular}{|l|r|r|r|r|}
\hline & SP5 & SP6 & SP7 & All \\
\hline Animate O's & 7 & 5 & 6 & 18 \\
\hline With prefix & 5 & 3 & 4 & 12 \\
\hline Proportion & $71 \%$ & $60 \%$ & $67 \%$ & $67 \%$ \\
\hline & & & & \\
\hline Inanimate O's & 7 & 5 & 5 & 17 \\
\hline With prefix & 4 & 2 & 1 & 7 \\
\hline Proportion & $57 \%$ & $40 \%$ & $20 \%$ & $41 \%$ \\
\hline
\end{tabular}

Looking at all three speakers, it seems that animacy is a good predictor for the presence of a prefix. The average for all three speakers is $67 \%$. But note also, that the proportion for indexed inanimate O's is quite high as well (41\%), as a sizable subset of inanimate O's is indexed. In that respect Adang is very different from Teiwa. In Teiwa, not a single inanimate $\mathrm{O}$ was indexed with a prefix in the experiment.

Therefore we believe that the results of our video elicitation task for Adang do not contradict Haan's (2001: 237) analysis of prefixed verbs as a closed (and implicitly) arbitrary verb class, which he calls "marked transitive verbs". In order not to conflate the concept of markedness with the expression in form in Adang, we refer to these as "prefixed transitive verbs". Haan does not give any semantic characterization of these verbs nor does he give semantic factors for prefixation. So while animacy has good 
predictive value, inanimate O's are indexed as well if they occur with a verb which belongs to the class of prefixed transitive verbs.

Prefixed transitive verbs always use a prefix from series I. These verbs form Class 1. An example is given in (22):

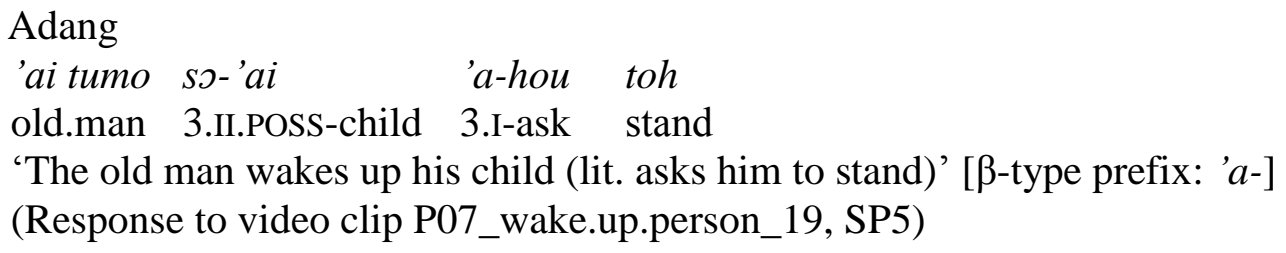

Other prefixed transitive verbs in Haan (2001) are: - ad 'release', - $a$ h 'feed', -ba'ang 'divide', -bung 'close to', -bunc 'admire', -danang 'wait for', -od 'stone', -dodo 'push', - eh 'bite', -hol 'know, find', -hou 'ask, command', -tan 'ask', -tan 'let'. This is a comprehensive list. The video elicitation task responses add -foh 'carry' and -den 'wake up' to this list. All of these verbs only occur with animate objects but there are other prefixed transitive verbs which do not follow this pattern. The following verbs always appear with a prefix but only have inanimate objects in Haan (2001): -bo' $x i$ 'cut', -lalung 'loosen', -nai 'between', -ten 'make'. The verb -tel 'lift up' either has an animate or an inanimate object. In the task, the following verbs were used with a prefix, regardless of whether they had an animate or an inanimate object: $-f a$, 'hug', $-d \varepsilon$ 'eat' and -bi'ing 'pull'. In total Adang has more prefixed verbs which appear with inanimate objects than Teiwa.

The second class of transitive verbs in Adang do not have prefixes and (with a very few exceptions, see below) only occur with inanimate objects. These verbs form Class 2. An example is (23):

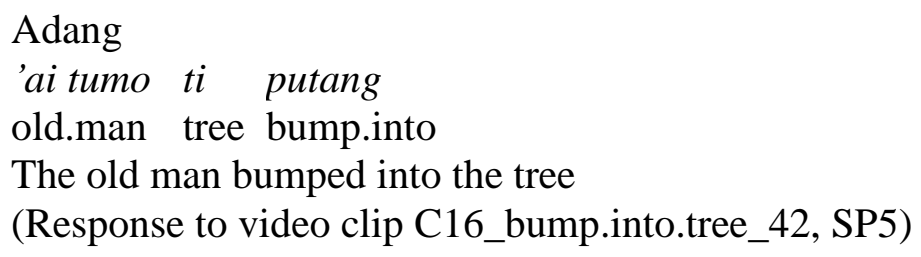

Other examples of unprefixed transitive verbs in Haan (2001) are: arung 'dig', dou 'cook', far '(be) under', fel 'buy', $f i$ ' 'spin', hul 'write', $h u$ ' 'measure', mang 'put on (clothing)', med 'take', meng 'put', mi '(be) in', msta '(be) above', na 'drink', pancn 'do, make', 'uhun 'pour', sapu 'clean', ta'on 'cut', ta'u 'steal', tarsp 'drop', tats' 'cut', tcfang 'carry on shoulder'; and from the video elicitation task: hafo' 'wash' and lam 'wash'. These only have inanimate objects.

Unprefixed transitive verbs in Haan (2001) which only occur with animate objects are: nod 'to tie (animals)', sibung 'forget', fit 'carry', luh 'hunt', ${ }^{10}$ masang 'shoot' and beh 'hit'; and from the task ba'ara' 'carry under arm'.

Verbs which can have an animate or an inanimate object but never index it in Haan (2001) are: hor 'injure', tu 'scratch', and ta 'be on'; and from the task: putung 'collide', ma'eh 'hear', tapang 'bump into', and baring 'pull'.

From the Adang corpus we know that a few transitive verbs alternate between Class 1 and 2. For a single verb stem, animate objects are indexed with a prefix, whereas inanimate objects are not. This only happens with -bang 'ask someone' vs. bang 'ask for something' (where the semantic relation between verb and object 
changes) and -pun 'catch/hold someone' vs. pun 'hold something' (where the semantic relation between verb and object stays the same'.

So far we have only dealt with one prefix series, namely series I, which is characterized by the vowel /a/. Adang has three other prefix series whose distribution is each restricted to a relatively small number of verbs. The series II $(/ \mathrm{o} /)$, III $(/ \varepsilon /)$, and IV (/el/) are formally distinct from series I but clearly related. ${ }^{11}$

According to Haan (2001: 292), series II is only used with one verb -lap 'look for', where the object needs to be human, typically a kin relation. ${ }^{12}$ Compare:

(24) Adang

Bain mang karesang seng lap bi'

PN only work money look.for a.lot

'Bain works too hard making money.' (Haan 2001: 357)

(25) Adang

Rudy 'o-lap-am?

PN 3.II-look.for-PFV

'Rudy has gone to him/her.' [ $\beta$-type prefix: 'o-]

(Haan 2001: 292)

In the video elicitation task, series II was used by two speakers to express the notion 'run to a person':

(26) Adang

'ai 'sb ka'ai nu te'eng ho' so-mang 'o-lap

child woman small one run come 3.II.POSS-father 3.II-look.for

'A little girl is running towards her father.' [ $\beta$-type prefix: 'o-]

(Response to video clip C12_run.to.person_20, SP6)

Although not descriptions of the key events in the clips, the following two verbs were used with series-II prefixes in the responses: $-l \supset f \varepsilon$ 'call to' and - 'stain 'release to'.

Series III was not used in the video elicitation task. It increases the valence of a verb by one and has an allative meaning of motion towards a referent. Such additional arguments are almost always animate. An example is given for an intransitive verb (27) and a transitive verb (28):

(27) Adang

Bain sapad pun ne-ho'

PN machete hold 1SG.III-come

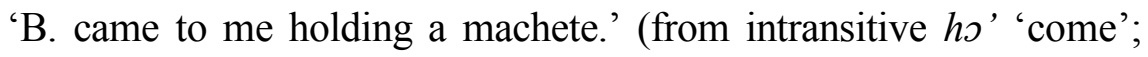

Haan 2001: 373)

(28) Adang

Ay af $\varepsilon \quad n \varepsilon^{-}$'a-t $\varepsilon l$

PN ladder 1sG.III-3.I-lift

'Ay lifted up the ladder toward me (to let me get down).' [ $\beta$-type prefix: 'a-]

(from transitive - $t \varepsilon l$ 'lift'; Haan 2001: 287) 
Intransitive verbs which take a prefix from series III, thereby becoming transitive, are -bad 'happy because of' (from bad 'happy'), -bune 'angry with' (from bune 'hot'),

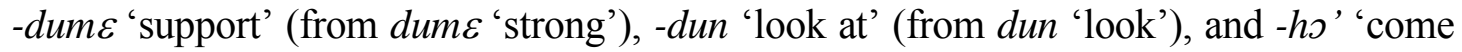
to' (from ho' 'come').

Unprefixed transitive verbs which take a series-III prefix, thereby becoming ditransitive are -maring 'tell to' (from maring 'tell'), -meng 'put for' (from meng 'put'), -hor 'wound (from hor 'cut, wound'), - 'uhun 'pour' (from 'uhun 'pour towards'), -arung 'dig (a hole) for' (from arung 'dig', -haleng 'hang (a rope) for' (from halcng 'hang'), and -muding 'plant (trap hooks) for' (from muding 'plant').

A few prefixed transitive verbs can take a series-III prefix in addition to a series-I prefix, thereby becoming ditransitive with two prefixes (indicated by the double dash I front of the verb root). These are - $-b \jmath^{\prime}$ ' $i$ 'cut towards' (from - $b \jmath^{\prime} i^{\prime}$ 'cut'), - $t \varepsilon l$ 'lift up towards' (from -tel 'lift up'), and - -hou 'ask for' (from -hou 'ask').

The $e l$-prefix series (IV) was only used with a single verb in the video elicitation task, namely -baroc 'be afraid of':

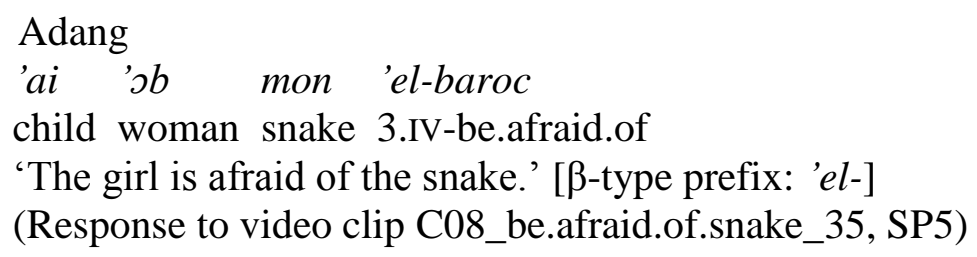

Verbs which take the IV-series form a very small closed class (Haan 2001: 284), comprising four items: -baroc 'afraid of' (from baroc 'afraid'), -t $\varepsilon$ ' $\varepsilon n g$ 'run from' (from $t \varepsilon$ ' $\varepsilon n g$ 'run'), -mala 'be shy about' (from mala 'shy'), and -tafuning 'hide from' (from tafuning 'hide'). The first three of these are intransitive verbs, the fourth one can be used intransitively, tafuning 'hide', or transitively, tafuning 'hide something'.

To sum up, in Adang the role of animacy is less discriminatory than in Teiwa but it is still observable in frequency. However, the distribution of prefixes is more dependent on the class of verb. While there are some Adang verbs that typically have an animate object and have a prefix, there are others which typically have an inanimate object and nonetheless index it with a prefix.

\subsection{Animacy in Kamang}

Animacy appears to be important in Kamang, which, from our video stimuli experiments at least, has a greater preference for prefixation of transitive verbs than Teiwa or Adang.

Table 7. Prefixation in 2-place predicates in Kamang

\begin{tabular}{|l|r|r|r|r|r|}
\hline & SP12 & SP13 & SP14 & SP15 & All \\
\hline 2-place predications & 15 & 11 & 15 & 13 & 54 \\
\hline Prefixed & 12 & 8 & 11 & 11 & 42 \\
\hline Proportion & $80 \%$ & $73 \%$ & $73 \%$ & $85 \%$ & $78 \%$ \\
\hline
\end{tabular}


Of the verbs associated with a two-place predication, 78\% (42/54) of the responses for all speakers were prefixed. The proportion of prefixed transitive verbs in the responses did vary across speakers.

Table 8. Prefixation of animate O's in Kamang

\begin{tabular}{|l|r|r|r|r|r|}
\hline & SP12 & SP13 & SP14 & SP15 & All \\
\hline Animate O & 8 & 5 & 7 & 7 & 27 \\
\hline Prefixed & 7 & 4 & 6 & 6 & 23 \\
\hline Proportion & $88 \%$ & $80 \%$ & $86 \%$ & $86 \%$ & $85 \%$ \\
\hline
\end{tabular}

For every speaker the proportion of transitive verbs which are prefixed when the object is animate is greater than the proportion of all prefixed verbs taken as a subset of all transitives, as can be seen by comparing table 8 with table 7 . Bringing all responses together, when the object is animate $85 \%$ (23/27) of transitive verbs are prefixed. Example (30) shows an animate O indexed with $g a-$ :

(30) Kamang

ge-taa dii ak ge-pa=l sue ga-tan

3.III-sleep lay.down DEF 3.III-father=CONTR.FOC arrive 3.I-wake.up

' $(\mathrm{He})$ is lying down and his father comes and wakes him.'

(Response to video clip P07_wake.up.person_19, SP15)

Kamang has six prefix series. The use of these varies in relation to animacy according to the role encoded by the prefx. The wo-series (series II) is almost exclusively used with transitives, and wo- is also the most frequently occurring prefix in the responses to the video stimuli. It accounts for just over half of all instances of prefixation of transitive verbs (22/42). Most importantly, in light of our claim that animacy favours prefixation, the $w o$-series actually favours inanimates. An example is given in (31):

(31) Kamang

bong ak wo-kawii

tree DEF 3.II-embrace

'(He) hugs the tree.'

(Response to video clip P13_hold.tree_28, SP15)

In contrast, for the $g a$-series (series I) the greatest proportion involve animate objects, namely $79 \%$ (11/14). From the video stimuli this also appears to be true for the $g e-$ series (series III), namely $83 \%(5 / 6)$, but this count is restricted to a very limited number of verbs, in particular beta 'push away' as illustrated in (32).

(32) Kamang

lami saak nok sue ge-nok ge-beta

husband old one arrive 3.III.POSS-friend 3.III-push.away

'An old man comes and pushes away his friend.'

(Response to video clip C13_bump.into.person_38, SP12)

The most important generalizations for the video stimuli results are those in (33). 
(33) a. In Kamang, if an $\mathrm{S}$ is indexed, it is animate.

b. The prefix series used to index animate O's ( $g a$ - and $g e-$ ) can be used to mark animate S's.

c. The prefix series used to index inanimate O's (wo-) is only very rarely used to mark animate S's.

Examples for S's that are indexed with $g a$ - and $g e$ - are (34) and (35), respectively.

(34) Kamang

alma nok nih-si=bo ga-sarang maa-ma

human one sit-IPFV=SEQ 3.I-get.up walk-PFV

'A person is sitting and then gets up and goes.'

(Response to video clip P21_stand.up_02, SP14)

(35) Kamang

alma nok ge-taa woo-pang

human one 3.III-sleep 3.VI-forget

'A person is sleeping peacefully.'

(Response to video clip C05_sleep_11, SP14)

Example (35) also illustrates the only response of an $\mathrm{S}$ indexed with the prefix woofrom the sixth pronoun series. Because only one verb -pang 'forget' was actually used with the prefix woo- (series VI), and we do not get any prefixes from the series IV or $\mathrm{V}$ in the responses to the video elicitation task, we are not in a position to say anything about their distribution or function here.

If we consider generalization (33b) this could be interpreted as an (almost) ergative-absolutive patterning, perhaps surprisingly, associated with being animate. In fact, where the single argument of intransitives is inanimate the verb is always unprefixed in the video-elicitation data, although counterexamples to this can be found in a wider dataset. While animacy appears to play an important role, the effects in Kamang differ from Teiwa. For Kamang the relationship in (33b) holds for the $g a$ series, while there is no connection between animate O's and intransitive S's in Teiwa. ${ }^{13}$ Furthermore, while Teiwa might be considered a typological rarity for indexing O's only, it does at least fit the generalization that it will be atypical object types which are indexed. That is, animates are less likely to be O's than inanimates and so it is more important to index them. In fact, in Kamang, the generalization that S's have to be animate in order to be prefixed is the mirror image of this. At this point, of course, functional explanations based on the need to express the unexpected value of the argument fall down.

\subsection{Animacy in Abui}

In Abui, as in the other languages under investigation, being a two-place predicate favours prefixation with an average of $83 \%$ between the four speakers. Animacy is of even higher importance for two-place predicates than in Kamang. All animate O's are indexed with a prefix (Table 9). So while Teiwa typically indexes animate O's but leaves many animate O's un-indexed, Abui also typically indexes animate O's and in addition many inanimate O's. In the experiment Abui speakers used verb prefixes 
with all animate objects, but there are cases in the Abui corpus where animate O's are not indexed.

Table 9. Indexation of animate O's in Abui (responses to the video stimuli)

\begin{tabular}{|l|r|r|r|r|r|}
\hline & SP8 & SP9 & SP10 & SP11 & All \\
\hline Animate O & 7 & 4 & 5 & 5 & 21 \\
\hline Prefixed & 7 & 4 & 5 & 5 & 21 \\
\hline Proportion & $100 \%$ & $100 \%$ & $100 \%$ & $100 \%$ & $100 \%$ \\
\hline
\end{tabular}

Abui has three distinct (but formally related) series of prefixes used for non-volitional participants (or participants of less volitionality) in transitive or intransitive clauses. ${ }^{14}$ The choice of prefix depends on a number of semantic considerations. A rough semantic characterization of the argument roles indexed by these three prefix series is as follows (based on Kratochvíl 2007: 190; Kratochvíl 2011):

- Series $\mathrm{I}^{15}$ (prefix $h a$-) is used for highly affected animate or inanimate patients undergoing a change of state, e.g. ha-dik [3.I-prick] 'pierce through it'.

- Series II (prefix ho-) is employed for individuated (mainly animate) patients (or themes) not undergoing a change of state, e.g. ho-dik [3.IIprick] 'poke, tickle him'.

- Series III (prefix $h e$-) is used for less affected participants (e.g. locations, benefactives, purposes, or propositions). Series-III prefixes are mainly used with inanimates but also with human/animate recipients, e.g. he-dik [3.IIIprick] 'stab (at) it'.

While series II is preferred for animates, series I is used with affected O's that undergo a change of state. Series III does not have this meaning of change of state. For more examples illustrating the semantic impact of prefix choice, see Kratochvíl (2007: 187-199).

For each series of prefixes Abui has two contrasting types for the third person. One of these types has the forms $d a-, d o-$, and $d e$ - ( $\alpha$-type); it indexes the actor. ${ }^{16}$ The other type has the forms $h a-$, ho-, and he- ( $\beta$-type); it indexes an undergoer. The difference between the $\alpha$-type and the $\beta$-type is illustrated by the following two examples:

(36) Abui

Fani el da-wel-i

PN before 3.I-pour-PFV

'Fani washed himself.' [ $\alpha$-type prefix: $d a$-]

(Kratochvíl 2007: 185)

(37) Abui

Fani el ha-wel-i

PN before 3.I-pour-PFV

'Fani washed him.' [ $\beta$-type prefix: ha-]

(Kratochvíl 2007: 185) 
In the responses to the video elicitation task, $\alpha$-type pronouns were only used in descriptions of one-participant events. The use of $\alpha$-type pronouns will be discussed below under the heading volitionality.

The $\beta$-type ( $h a-$ ) is only used to index objects in the description of two-participant events and is only used for objects in events with volitional A's. An example is given in (38):

(38) Abui

wil neng nuku di de-fela ha-fik ha-bel-e

child male one 3ACT 3.III.POSS-friend 3.I-pull 3.I-pull-IPFV

'A boy is pulling his friend.' [ $\alpha$-type prefix: $h a$-]

(Response to video clip C01_pull.person_25, SP8)

The animacy of the object does not have any impact on the choice of $h a$ - over the other prefixes of the $\beta$-type. The form ha-fik was also consistently chosen when the participant being pulled was a log.

The prefix he-was very consistently used by all four speakers to index the house as the inanimate object of the verb -haabi 'lean on' in the response to the stimulus (C21_lean.on.house_27). The prefix ho- is likewise used for O's only. It indexes either an animate or an inanimate object on the verbs -bakei 'hug' and -yaari 'bump', an animate object on the verbs -munang 'smell' and -pang 'touch', and an inanimate object on the verb -fahake 'hold'.

Inanimacy also plays a role in the indexing patterns of transitive verbs. There is one class of verbs which never have a prefix in the corpus and which exclusively occur with an inanimate O, e.g. baai 'grind', bang 'carry', buuk 'drink', kadel 'split', lang 'wash', mihi 'set down', nee 'eat', tur 'scoop', and wit 'carry in arms'. In the experiment, all unprefixed verbs which were used for the description of twoparticipant events had inanimate O's.

\subsection{Volitionality}

The second property we discuss in this paper is volitionality of the only argument (S) in one-place predications and of the A argument in two-place predications.

In Teiwa, the number of prefixes used is too small to say anything reliable about the possible impact of (non-)volitionality on prefixation.

In Adang, non-volitionality favours the absence of a prefix in two-place predicates (Table 10). 
Table 10. Proportion of prefixed verbs depending on volitionality of A in Adang twoplace predicates (responses to the video stimuli)

\begin{tabular}{|l|r|r|r|r|}
\hline & SP5 & SP6 & SP7 & All \\
\hline Volitional A & 7 & 8 & 8 & 23 \\
\hline Prefixed & 6 & 5 & 4 & 15 \\
\hline Proportion & $86 \%$ & $63 \%$ & $50 \%$ & $65 \%$ \\
\hline & & & & \\
\hline Non-volitional A & 7 & 2 & 3 & 12 \\
\hline Prefixed & 3 & 0 & 1 & 4 \\
\hline Proportion & $43 \%$ & $0 \%$ & $33 \%$ & $33 \%$ \\
\hline
\end{tabular}

Volitionality of the A argument in two-place predicates in Adang favours prefixation (65\%), whereas there is a lower proportion of prefixes with non-volitional A's (33\%).

In Kamang volitionality appears to favour prefixation to some extent. ${ }^{17}$ For transitive verbs with volitional A's 72\% (31/43) were prefixed in the video stimuli. For intransitive verbs with volitional S's (all of which are also animate) the proportion is $35 \%(8 / 23)$, but this is actually greater than for intransitives as a whole, namely $19 \%(10 / 54)$ and much greater than for non-volitional S's, namely only $6 \%(2 / 31)$. In fact, volitional S's show by far the highest proportion of prefixation. This is in contrast to Abui, to which we now turn, where it is exactly the non-volitional animate S's which are indexed.

In Abui, volitionality is an important factor. Abui is a language with semantic alignment, i.e. semantic features of core arguments, such as volitionality, instigation of an action, and affectedness, have an impact on the way the argument(s) are marked, both in terms of whether a free pronoun or a bound prefix is used, and if the latter, which prefix series is employed (Kratochvíl 2007: Ch. 5; Kratochvíl 2011; Kratochvíl to appear).

Abui is the language with the most instances of prefixation of the $S$ argument in one-place predicates (Table 11).

Table 11. Indexation of S's in one-place predicates in Abui (responses to the video stimuli)

\begin{tabular}{|l|r|r|r|r|r|}
\hline & SP8 & SP9 & SP10 & SP11 & All \\
\hline One-place predicates & 17 & 12 & 10 & 12 & 51 \\
\hline Prefixed & 8 & 6 & 4 & 5 & 23 \\
\hline Proportion & $47 \%$ & $50 \%$ & $40 \%$ & $42 \%$ & $45 \%$ \\
\hline
\end{tabular}

A proportion of $45 \%$ is very high in comparison to Teiwa where S's were not indexed at all, to Adang where an average of $6 \%$ of S's were indexed, and to Kamang where an average of $19 \%$ of S's were indexed.

As we shall see, non-volitionality, when combined with animacy, appears to play a bigger role in prefixation in Abui intransitives than in any of the other languages. This is consistent with Kratochvíl's analysis of Abui as a semantically aligned language. Free pronouns are reserved for typical agents, i.e. participants who have volition with respect to the event and are not affected by it. The set of free pronouns includes the third person pronoun $d i{ }^{18}$ which can appear on its own or be adnominal following a noun phrase. In our experiment, there were no instances where an $\mathrm{S}$ was encoded with 
$d i$ in any of the responses. In all cases noun phrases without $d i$ were used, for example in (39):

(39) Abui

ama nuku furai ba weei

man one run and go

'A man is running along.'

(Response to video clip P20_run_06, SP8)

Other examples from the experiment are: mit 'sit', natet 'stand' and it 'lie'. Further examples from the Abui corpus are: ayong 'swim', kalol 'foretell (fortune or the future)', kawai 'argue', luuk 'dance', miei 'come', taa 'lie', yaa(r) 'go'. Semantically, these are mainly motion verbs, posture verbs, and social activities. Typically these express their $\mathrm{S}$ with a free pronoun and not a prefix because they typically have volitional arguments, but Kratochvíl (to appear) cautions: "The [Abui semantic alignment - the authors] system is highly fluid: virtually every verb can combine with different prefixes rendering distinct meanings".

On the other hand, the experiment showed that some verbs can indeed be used without a prefix even though the participant does not have volition with respect to the event, e.g. taa 'sleep', mok '(be) sleepy', takun 'go out (of flame)', yatul 'fall asleep', toral 'burn', die 'burn', and fok '(be) big'.

Free pronouns can be combined with a co-referent prefix (in the third person this needs to be an $\alpha$-type prefix) to express reflexive situations, in which the agent is volitional but also affected by his (own) action. As there are no examples of this construction in the responses to the video elicitation task, a textual example is given in (40):

(40) Abui

Ata di do-kafi-a

PN 3ACT 3.II-scrape-DUR

'A. scratches himself (intentionally).' [ $\alpha$-type prefix: $d o$-]

(Kratochvíl 2007: 203)

Non-volitional S's are expressed only with a prefix. An additional free pronoun is not possible.

(41) Abui

neng nuku laak-laak-i ba me la da-kaai yo eya!

man one walk-walk-PFV and come just 3.I-stumble DEM EXCLAM

'A man walks along and stumbles there, whoops!' [ $\alpha$-type prefix: $d o-]$

(Response to video clip P09_person.fall_14, SP 9)

In the responses to the video elicitation task, $\alpha$-type prefixes were exclusively used in the descriptions of one-participant events. In each case the prefix cross-references the sole argument of the verb. Prefixes of the $\alpha$-type are used with non-volitional S's, namely the S of minang 'wake up', liel 'tall', lal 'laugh', kaai 'stumble', and yongf 'forget' (which was employed in descriptions of the sleep event [i.e. video clip C05_sleep_11]). Speakers also very consistently used $\alpha$-type prefixes with volitional S's with the two positional verbs ruid 'rise, stand up' and reek 'lie'. 
(42) Abui

wil neng da-ruid-i ba laak-i

child male 3.I-stand.up-PFV and leave-PFV

'The guy stands up and leaves.' [ $\alpha$-type prefix: $d a$-]

(Response to video clip P21_stand.up_02, SP11)

Other $\alpha$-type prefixes were very rarely used in the video elicitation task. Two speakers used the prefix do- with the verb-hayoke 'shake' to describe the dancing-event and one speaker used the prefix de-with the verb -muil 'play' to describe the same dancing-event. Prefixes of the $\alpha$-type other than $d a$ - are too infrequent in the responses to draw any conclusions as to whether the choice between them depends on any of the semantic factors volitionality or animacy.

However, just looking at the effect of volitionality alone on the coding in the experiment does not give us a clear picture. The proportions for non-volitional and volitional S's are about equal (Table 12).

Table 12. Indexation of non-volitional and volitional S's in Abui (responses to the video stimuli)

\begin{tabular}{|l|r|r|r|r|r|}
\hline & SP8 & SP9 & SP10 & SP11 & All \\
\hline Non-volitional S & 11 & 6 & 4 & 6 & 27 \\
\hline Prefixed & 5 & 3 & 2 & 2 & 12 \\
\hline Proportion & $45 \%$ & $50 \%$ & $50 \%$ & $33 \%$ & $44 \%$ \\
\hline & & & & & \\
\hline Volitional S & 6 & 6 & 6 & 6 & 24 \\
\hline Prefixed & 3 & 3 & 2 & 3 & 11 \\
\hline Proportion & $50 \%$ & $50 \%$ & $33 \%$ & $50 \%$ & $46 \%$ \\
\hline
\end{tabular}

The impact of non-volitionality becomes more obvious when one looks at nonvolitional animate S's. Of all S arguments in one-place predications, non-volitional animate S's are most likely to be indexed (Table 13).

Table 13. Indexation of non-volitional animate S's in Abui (responses to the video stimuli)

\begin{tabular}{|l|r|r|r|r|r|}
\hline & SP8 & SP9 & SP10 & SP11 & All \\
\hline $\begin{array}{l}\text { Non-volitional } \\
\text { AND animate S }\end{array}$ & 6 & 4 & 3 & 3 & 16 \\
\hline Prefixed & 4 & 3 & 2 & 2 & 11 \\
\hline Proportion & $66 \%$ & $75 \%$ & $66 \%$ & $66 \%$ & $69 \%$ \\
\hline
\end{tabular}

In summary, then, in Abui animate S's that are non-volitional are indexed with a prefix for an average of $69 \%$ of the cases, whereas animate S's (55\%), volitional animate S's (46\%), and inanimate (and thus by definition non-volitional) S's (9\%) show much lower proportions. This pattern has a straightforward functional explanation since non-volitional animate S's are atypical. 


\section{Conclusion}

We have used video elicitation, combined with existing data, to determine the extent of variation associated with well known semantic factors in argument realization. The video elicitation task confirmed that certain of these factors play an important role in determining prefixation patterns in the Alor-Pantar languages we have investigated. Of the factors in question animacy, volitionality and the number of participants have an observable effect on the prefixation patterns. They have an impact on whether an argument is indexed with a prefix, and if a prefix is used, from which series it comes.

The role of animacy is observable across all the languages. In some languages it can be complemented by other factors, but even when these are absent, it can still be observed. This is true of Teiwa, where it is a typical condition for an object argument to be animate in order for it to be indexed by a prefix. In Adang, a language similar to Teiwa in its alignment, the role of animacy is less discriminatory but is still observable in frequency. Overlaid onto the animacy consideration is the greater association with verbal class in Adang. While there are some Adang verbs that typically have an animate object and have a prefix, there are others which typically have an inanimate object and nonetheless index it with a prefix. The distribution of prefixes in Adang is therefore more dependent on the class of verb itself.

In Kamang and Abui animacy is also important. For Kamang the large majority of animate objects (O's) are indexed with a prefix, and in Abui almost all animate objects are indexed. But additional factors come into play, in particular volitionality for one-place predicates. The role of volitionality is most readily observable in Kamang and Abui. In Kamang, volitionality favours prefixation. While indexation of intransitive subjects (S's) appears to be dispreferred overall in Kamang, more volitional intransitive subjects (S's) are prefixed in comparison to prefixed nonvolitional intransitive subjects (S's). Furthermore, there is interesting interaction of animacy and volitionality in Abui, where volitionality and animacy work together to increase the likelihood of the intransitive subject (S) being indexed on the verb. Table 14 summarizes these results.

Table 14. Summary of results

\begin{tabular}{|l|l|}
\hline Languages & Prefixation favoured with \\
\hline Teiwa & animate Os (and very few inanimate Os) \\
\hline Adang & animate Os (but also some inanimate Os) \\
\hline Kamang & animate Os and volitional animate Ss \\
\hline Abui & animate Os and non-volitional animate Ss \\
\hline
\end{tabular}

Our experimental method confirmed the fascination of the Alor-Pantar languages for understanding the role of the usual suspects in realizing grammatical relations. While it is possible to identify roles for the different factors, their influence is manifested in different ways and to different degrees. This is further evidence that it is impossible to assume a direct relationship between the semantics and the formal realization of argument marking. The experiment shows that none of these systems of argument indexation is semantically fully transparent. Being an animate object $(\mathrm{O})$ is not a sufficient condition for an argument to be indexed in Teiwa. Many animate objects (O's) are, in fact, not indexed and the number of verbs which alternate between 
having an animate object, which is indexed with a prefix, or having an inanimate object, which is not indexed or indexed with a different prefix, is quite small. We can observe variation in the influence of the different factors, from Adang, where there is a greater degree of arbitrariness, to Abui, where the role of the semantic factors is more direct. Only by using a controlled method, such as the video stimuli presented here, can such an in-depth comparison be made. 


\section{Appendix 1 - Pronoun paradigms}

In all the following tables brackets in prefix forms distinguish between pre-vocalic and pre-consonantal position.

\begin{tabular}{|l|l|l|l|l|}
\cline { 2 - 5 } \multicolumn{1}{c|}{} & \multicolumn{2}{c|}{ Subject } & \multicolumn{2}{c|}{ Object } \\
\cline { 2 - 5 } \multicolumn{1}{c|}{} & $\begin{array}{l}\text { Long } \\
\text { form }\end{array}$ & $\begin{array}{l}\text { Short } \\
\text { form }\end{array}$ & $\begin{array}{l}\text { Free } \\
\text { form }\end{array}$ & $\begin{array}{l}\text { Prefix } \\
\text { series }\end{array}$ \\
\hline 1SG & na'an & $n a$ & na'an & $n(a)$ - \\
\hline 2SG & ha'an & $h a$ & ha'an & $h(a)$ - \\
\hline 3SG & 'an & $a$ & ga'an & $g(a)$-, gə- \\
\hline 1PL.EXCL & $n i^{\prime}$ in & $n i$ & ni'in & $n(i)$ - \\
\hline 1PL.INCL & pi'in & $p i$ & pi'in & $p(i)$ - \\
\hline 2PL & yi'in & $y i$ & yi'in & $y(i)$ - \\
\hline 3PL & iman & $i, a$ & iman & $g(i)$-, ga- \\
\hline 3PL.ELSEWH. & $i^{\prime}$ 'in & $i, a$ & gi'in & $g(i)$ - \\
\hline DISTRIB. & ta'an & ta & ta'an & $t(a)$ - \\
\hline
\end{tabular}

Table A. Teiwa free pronouns and prefixes (Klamer 2010)

\begin{tabular}{|c|c|c|c|c|c|c|c|}
\hline & \multicolumn{3}{|c|}{ Free pronouns } & \multicolumn{4}{|c|}{ Prefix series } \\
\hline & NOM & $\mathrm{ACC}$ & GEN & $\mathrm{I}$ & II & III & IV \\
\hline $1 \mathrm{SG}$ & $n a$ & $n a-r i$ & no/ne & $n(a)-$ & no- & $n \varepsilon-$ & nel- \\
\hline $2 \mathrm{SG}$ & $a$ & $a-r i$ & o/e & $a-$ & $0-$ & $\varepsilon-$ & el- \\
\hline 3SG ( $\alpha$-type) & \multirow{2}{*}{$s a$} & sa-ri & so/se & $s(a)-$ & So- & $s \varepsilon-$ & sel- \\
\hline 3SG ( $\beta$-type) & & 'a-ri & 'כ'e & '(a)- & ’’- & ${ }^{\prime} \varepsilon_{-}^{-}$ & 'el- \\
\hline $2 \mathrm{PL}$ & $i$ & $i-r i$ & $i / i(e)$ & $i-$ & is- & $i \varepsilon-$ & iel- \\
\hline 1PL EXCL & $n i$ & $n i-r i$ & ni/ni(e) & $n i-$ & nis- & $n i \varepsilon-$ & niel- \\
\hline 1PL INCL COLL & \multirow[b]{2}{*}{$p i$} & $p i-r i$ & pi/pi(e) & \multirow[b]{2}{*}{$p i-$} & \multirow[b]{2}{*}{ pio- } & \multirow[b]{2}{*}{ pie- } & \multirow[b]{2}{*}{ piel- } \\
\hline $\begin{array}{l}\text { 1PL INCL } \\
\text { DISTR }\end{array}$ & & ta-ri & to/te & & & & \\
\hline 3PL ( $\alpha$-type $)$ & \multirow[b]{2}{*}{ supi } & $s a-r i$ & so/se & $s(a)-$ & so- & $s \varepsilon-$ & sel- \\
\hline 3PL ( $\beta$-type) & & supi ('a-ri) & $\begin{array}{l}\text { supi 'כ' } \\
\text { supi 'e }\end{array}$ & '(a)- & ’- & ' $\varepsilon^{-}$ & 'el- \\
\hline
\end{tabular}

Table B. Adang free pronouns and prefixes (Haan 2001, prefix forms reanalyzed into four separate series - the authors)

\begin{tabular}{|c|c|c|c|c|c|c|c|}
\hline & \multirow{2}{*}{$\begin{array}{l}\text { Free (basic) } \\
\text { pronoun }\end{array}$} & \multicolumn{6}{|c|}{ Prefix series } \\
\hline & & I & II & III & IV & $\mathrm{V}$ & VI \\
\hline $1 \mathrm{SG}$ & $n a$ & $n a-$ & no- & $n e-$ & nee- & nao- & noo- \\
\hline $2 \mathrm{SG}$ & $a$ & $a-$ & $O-$ & $e-$ & $e e-$ & $a o-$ & $O O-$ \\
\hline 3 & $g a$ & $g a-$ & wo- & $g e-$ & gee- & gao- & woo- \\
\hline 1PL.EXCL & $n i$ & $n i-$ & nio- & $n i-$ & $n i i-$ & nio- & nioo- \\
\hline 1PL.INCL & $s i$ & $s i-$ & sio- & $s i-$ & sii- & sio- & sioo- \\
\hline $2 \mathrm{PL}$ & $i$ & $i$ - & io- & $i-$ & $i i-$ & io- & ioo- \\
\hline COMMON & $t a$ & $t a-$ & to- & te- & tee- & tao- & too- \\
\hline
\end{tabular}

Table C. Kamang free pronouns and prefixes 


\begin{tabular}{|c|c|c|c|c|}
\hline & \multirow{2}{*}{$\begin{array}{l}\text { Free } \\
\text { pronoun }\end{array}$} & \multicolumn{3}{|c|}{ Prefix series } \\
\hline & & $\mathrm{I}$ & II & III \\
\hline $1 \mathrm{SG}$ & $n a$ & $n(a)-$ & no- & ne- \\
\hline $2 \mathrm{SG}$ & $a$ & $a-(\emptyset$ - before V) & $O-$ & $e-$ \\
\hline 3 ( $\alpha$-type) & & $d(a)-$ & do- & $d e-$ \\
\hline 3 ( $\beta$-type) & $d l$ & $h(a)-$ & ho- & he- \\
\hline 1PL.EXCL & $n i$ & $n i-$ & $n u-$ & $n i-$ \\
\hline 1PL.INCL & $p i$ & $p i-$ & $p o-/ p u-$ & $p i-$ \\
\hline $2 \mathrm{PL}$ & $r i$ & $r i-$ & ro-/ru- & ri- \\
\hline DISTR & & $t(a)-$ & to- & te- \\
\hline
\end{tabular}

Table D. Abui free pronouns and prefixes (Kratochvíl 2007) 


\section{Appendix 2 - List of video clips (members of the core set in boldface)}

\begin{tabular}{|c|c|c|c|c|c|c|}
\hline$\underline{\mathbf{P}}$ & Vol & Tel An & Stat & Event & Description & Clip file name \\
\hline 1 & vol & tel an & dyn & 1 sit down & Person sitting down. & C14_sit.down_01 \\
\hline 1 & vol & tel an & dyn & 2 stand up & Person standing up. & P21_stand.up_02 \\
\hline 1 & vol & atel an & stat & 3 stand & Person standing. & P17_stand_03 \\
\hline 1 & vol & atel an & stat & 4 lie & Person lying on the ground. & C10_lie_04 \\
\hline 1 & vol & atel an & dyn & 5 dance & People dancing. & C03_dance_05 \\
\hline 1 & vol & atel an & dyn & 6 run & $\begin{array}{l}\text { Person running from the off } \\
\text { into the off. }\end{array}$ & P20_run_06 \\
\hline 1 & \multirow{2}{*}{\multicolumn{2}{|c|}{$\begin{array}{l}\text { non-vol tel an } \\
\text { non-vol tel an }\end{array}$}} & dyn & 7 wake up & Person waking up suddenly. & P04_wake.up_07 \\
\hline 1 & & & dyn & 8 fall asleep & Person sitting, falling asleep. & C06_fall.asleep_08 \\
\hline 1 & \multirow{2}{*}{\multicolumn{2}{|c|}{$\begin{array}{l}\text { non-vol tel inan } \\
\text { non-vol tel inan }\end{array}$}} & dyn & 9 fill up & Glass being filled from bottle. & C09_fill.up_09 \\
\hline 1 & & & dyn & 10 go out & Flame goes out. & P03_go.out_10 \\
\hline 1 & \multirow{2}{*}{\multicolumn{2}{|c|}{$\begin{array}{l}\text { non-vol atel an } \\
\text { non-vol atel an }\end{array}$}} & stat & 11 sleep & Person sleeping. & C05_sleep_11 \\
\hline 1 & & & stat & 12 be tall & Two people, one tall and one short. & P05_be.tall_12 \\
\hline 1 & \multirow{2}{*}{\multicolumn{2}{|c|}{$\begin{array}{l}\text { non-vol atel an } \\
\text { non-vol atel an }\end{array}$}} & dyn & 13 laugh & Person laughing. & C07_laugh_13 \\
\hline 1 & & & dyn & 14 fall & Person slipping and falling. & P09_person_fall_14 \\
\hline 1 & \multirow{2}{*}{\multicolumn{2}{|c|}{$\begin{array}{l}\text { non-vol atel inan } \\
\text { non-vol atel inan }\end{array}$}} & stat & 15 be big & One big and two small stones. & P18_be.big_15 \\
\hline 1 & & & stat & 16 be long & One long and three short logs. & C17_be.long_16 \\
\hline 1 & \multirow{2}{*}{\multicolumn{2}{|c|}{$\begin{array}{l}\text { non-vol atel inan } \\
\text { non-vol atel inan }\end{array}$}} & dyn & 17 fall & Coconut falling. & C15_fall_17 \\
\hline 1 & & & dyn & 18 burn & Burning house. & P10_burn_18 \\
\hline 2 & vol & tel an & dyn & 19 wake s.o. up & Person waking another person up. & P07_wake.up.person_19 \\
\hline 2 & vol & tel an & dyn & 20 run to s.o. & Child running to parent. & C12_run.to.person_20 \\
\hline 2 & vol & tel inan & dyn & 21 eat sth. & Person eating a banana. & C11_eat.banana_21 \\
\hline 2 & vol & tel inan & dyn & 22 wash sth. & Person washing plate. & P16_wash.plate_22 \\
\hline 2 & vol & atel an & stat & 23 lean on s.o. & Child leaning on parent. & C02_lean.on.person_23 \\
\hline 2 & vol & atel an & stat & 24 hold s.o. & Person holding child. & P15_hold.person_24 \\
\hline 2 & vol & atel an & dyn & 25 pull s.o. & A pulling $B$. & C01_pull.person_25 \\
\hline 2 & vol & atel an & dyn & 26 smell s.o. & A sniffing at $\mathrm{B}$, disgusted face . & P01_smell.person_26 \\
\hline 2 & vol & atel inan & stat & 27 lean on sth. & Person leaning on house. & C21_lean.on.house_27 \\
\hline 2 & vol & atel inan & stat & 28 hold sth. & Person hugging a tree. & P13_hold.tree_28 \\
\hline 2 & vol & atel inan & dyn & 29 pull sth. & Child pulling a log. & C18_pull.log_29 \\
\hline 2 & vol & atel inan & dyn & 30 smell sth. & Person sniffing at food, disgusted face. & P02_smell.food_30 \\
\hline 2 & non- & tel an & dyn & 31 fall onto s.o. & Banana drops on person's stomach. & P19_fall.onto.person_31 \\
\hline 2 & non- & tel an & dyn & 32 step on s.o. & Child stepping on lying person. & C04_step.on.person_32 \\
\hline 2 & non- & tel inan & dyn & 33 step on sth. & Person stepping on a banana. & C20_step.on.banana_33 \\
\hline 2 & non- & tel inan & dyn & 34 fall onto sth. & Banana falling onto log. & P11_fall.onto.log_34 \\
\hline 2 & non- & atel an & stat & 35 be afraid of s.o. & Child afraid of snake. & C08_be.afraid.of.snake_35 \\
\hline 2 & non- & atel an & stat & 36 bend person & Rock bending someone's back. & P08_bend.person_36 \\
\hline 2 & non- & atel an & dyn & 37 hear s.o. & A hears B calling out and turns head. & P12_hear.person_37 \\
\hline 2 & non- & atel an & dyn & 38 bump into s.o. & A bumping into $B$. & C13_bump.into.person_38 \\
\hline 2 & non- - & atel inan & stat & 39 bend sth. & Log lying on a plank bending it. & P14_bend.plank_39 \\
\hline 2 & non- & atel inan & stat & 40 be afraid of sth. & Person afraid of axe. & C19_be.afraid.of.axe_4 \\
\hline 2 & non- - & atel inan & dyn & 41 hear sth. & A hears noise and turns head. & P06_hear.noise_41 \\
\hline 2 & non- & atel inan & dyn & 42 bump into sth. & Person walking into a tree. & C16_bump.into_tree_42 \\
\hline
\end{tabular}




\section{Appendix 3 - Figures for telicity}

Here we give some data from our experiment which suggest that being atelic has an effect on argument indexing in Abui and Kamang. The effects appear to be dependent on participant number. Abui shows an effect only in transitive verbs whereas Kamang shows an effect only in intransitive verbs. In Abui all transitives atelic verbs are prefixed. In Kamang intransitives atelicity very strongly disfavours prefixation. In either language being telic does not seem to predict much in terms of whether a verb has a prefix or not.

Table E. Atelicity and indexation in Abui transitive verbs

\begin{tabular}{|l|r|r|r|r|r|}
\hline & SP8 & SP9 & SP10 & SP11 & All \\
\hline Two-participant, atelic & 12 & 6 & 8 & 7 & 33 \\
\hline With prefix & 12 & 6 & 8 & 7 & 33 \\
\hline Proportion & $100 \%$ & $100 \%$ & $100 \%$ & $100 \%$ & $100 \%$ \\
\hline & & & & & \\
\hline Two-participant, telic & 4 & 4 & 3 & 4 & 15 \\
\hline With prefix & 2 & 2 & 1 & 2 & 7 \\
\hline Proportion & $50 \%$ & $50 \%$ & $33 \%$ & $50 \%$ & $47 \%$ \\
\hline
\end{tabular}

Table F. Atelicity and indexation in Kamang intransitive verbs

\begin{tabular}{|l|r|r|r|r|r|}
\hline & SP12 & SP13 & SP14 & SP15 & All \\
\hline One-participant, atelic & 10 & 10 & 11 & 11 & 42 \\
\hline With prefix & 0 & 0 & 3 & 2 & 5 \\
\hline Proportion & $0 \%$ & $0 \%$ & $27 \%$ & $18 \%$ & $12 \%$ \\
\hline & & & & & \\
\hline One-participant, telic & 3 & 3 & 3 & 3 & 12 \\
\hline With prefix & 1 & 1 & 2 & 1 & 5 \\
\hline Proportion & $33 \%$ & $33 \%$ & $66 \%$ & $33 \%$ & $42 \%$ \\
\hline
\end{tabular}

\section{Notes}

${ }^{1}$ Sebastian Fedden and Dunstan Brown wrote the paper. Sebastian Fedden, Dunstan Brown, and Greville Corbett designed the video stimuli that were used in the experiment. Gary Holton, Marian Klamer, Laura C. Robinson, and Antoinette Schapper co-ordinated and carried out the experiments in the field and provided the data. We would like to thank Ger Reesink for helpful suggestions about the cultural appropriateness of the video clips when he attended one of our project meetings. We would like to thank Matthew Baerman, Michael Dunn, Nick Enfield, Nick Evans, and Asifa Majid for helpful discussion about experimental setup and video clip design. We are grateful to two anonymous reviewers for Linguistics. This paper was presented at the EuroBabel cross-CRP meeting on Referential hierarchy effects on the morphosyntax of verbal arguments in Leipzig, August 28-29, 2010, the annual meeting of the Linguistics Association of Great Britain (LAGB) 2010 in Leeds, September 1-4, 2010, and the University of Cologne on February 2, 2011. We would like to thank the respective audiences for helpful comments and discussion. The work reported here was supported under the European Science Foundation's EuroBABEL programme (project 'Alor-Pantar languages: origin and theoretical impact'). Fedden, Brown, and Corbett were funded by the Arts and Humanities Research Council (UK) under grant AH/H500251/1. Holton and Robinson were funded by the National Science Foundation (US) under BCS Grant No. 0936887. Klamer and Schapper were funded by the Netherlands Organisation for Scientific Research (NWO). We thank these funding bodies for their 
support. Correspondence address: Sebastian Fedden, Surrey Morphology Group, School of English and Languages, University of Surrey, Guildford GU2 7XH, UK. E-mail: s.fedden@surrey.ac.uk.

${ }^{2}$ List of abbreviations: $1-1^{\text {st }}$ person, $2-2^{\text {nd }}$ person, $3-3^{\text {rd }}$ person, I - Prefix series I, II - Prefix series II, III - Prefix series III, IV - Prefix series IV, V - Prefix series V, VI - Prefix series VI, ACC Accusative, ACT - Actor, AN - Animate, CONTR - Contrastive, DEF - Definite, DEM Demonstrative, DUR - Durative, EXCLAM - Exclamative, FOC - Focus, GEN - Genitive, IPFV Imperfective, NOM - Nominative, OBL - Oblique, PFV - Perfective, PN - Proper name, POSS Possessor, PROG - Progressive, REAL - Realis, SEQ - Sequential, SG - Singular, SIM Simultaneous, SP - Speaker.

${ }^{3}$ The abbreviations are Tw - Teiwa, Nd - Nedebang, Ke - Kaera, WP - Western Pantar, Bl - Blagar, Ad - Adang, Kl - Klon, Ki - Kui, Ab - Abui, Km - Kamang, Sw - Sawila, We - Wersing.

${ }^{4}$ Similar prefixes occur on nouns to mark possession. There are parallels, particularly because inalienable possession usually involves animate possessors linearly preceding the possessum in the same way that objects linearly precede the verb. But as our focus here is on examining the role of the different factors with verbs, we will not consider possession marking further.

${ }^{5}$ We define 'telic' loosely as "denoting a change of state" and 'atelic' as an "unbounded process or activity".

${ }^{6}$ We use the definition given by Comrie (1976: 49): "With a state, unless something happens to change that state, then the state will continue [...]. With a dynamic situation, on the other hand, the situation will only continue if it is continually subject to a new input of energy [...]".

${ }^{7}$ The field experimenters are Gary Holton (for Western Pantar), Marian Klamer (for Teiwa), Laura Robinson (for Adang and Teiwa), Antoinette Schapper (for Abui and Kamang).

${ }^{8}$ For SP2, there were two secondary speakers present during the elicitation session. For SP3 and SP4 there was a further secondary speaker present at each of their sessions.

${ }^{9}$ Haan (2001: 52) uses the terms 'proximal' and 'obviative' for the pronouns in the third person. In order to avoid the assumptions which come with the standard terms 'proximate' and 'obviative', where the degree of topicality or remoteness might be suggested, we use the designations $\alpha$-type and $\beta$-type.

${ }^{10}$ This verb normally takes the object $n a$ 'thing'. There is a traditional belief that names of animals should not be used lest the hunters have bad luck (Haan 2001: 226).

${ }^{11}$ Haan $(2001: 282,292)$ analyzes these as segmentable sequences of a pronominal prefix (which loses it /a/-vowel in front of a vowel) followed by some applicative element $-\varepsilon$ 'allative', - $\supset$ 'possessive allative' and -el 'ablative'. Our treatment is non-committal as to the semantics of the formative. We therefore treat them in terms of different prefix series.

${ }^{12}$ Series II plays a more important role in nominal possession.

${ }^{13} \mathrm{We}$ can only compare the $g a$-series because this is the only series Teiwa has.

${ }^{14}$ Recent fieldwork has indicated that there might be two more prefix series in Abui. Given the paucity of data on this matter, we are not in a position to take these recent findings into account in this article.

${ }^{15}$ Kratochvíl (2007; 2011) calls the three series Patient (PAT), Recipient (REC), and Locative (LOC), respectively. As we do not want to assume too much about the semantics of the prefixes, we use the more non-committal number designations.

${ }^{16}$ Kratochvíl (2007: 78-79) call these '3I' (our $\alpha$-type) and '3II' (our $\beta$-type), respectively.

${ }^{17}$ These video experiment results do not cover an optional use of the series II prefix ge- for which corpus work indicates that it can play a part in indicating that a single argument of the verb was forced or caused to be in a particular state. This can occur with the verb 'lie' for instance.

${ }^{18}$ The free pronoun $d i$ is probably of verbal origin and has grammaticalized from the auxiliary $d$ 'hold' (Kratochvíl 2011). Participants marked with $d i$ are mainly humans, but non-human participants of considerable agentive force, e.g. a storm, are also possible. 


\section{References}

Aissen, Judith. 2003. Differential object marking: Iconicity vs. economy. Natural Language \& Linguistic Theory 21(3). 435-448.

Arkadiev, Peter. 2008. Thematic roles, event structure, and argument encoding in semantically aligned languages. In Mark Donohue \& Søren Wichmann (eds.), The typology of semantic alignment, 101-117. Oxford: Oxford University Press.

Baayen, R. Harald. 1992. Quantitative aspects of morphological productivity. In Geert Booij \& Jaap van Marle (eds.), Yearbook of Morphology 1991, 109-149. Dordrecht: Kluwer Academic Publishers.

Baird, Louise. 2008. A grammar of Klon: A non-Austronesian language of Alor, Indonesia (Pacific Linguistics 596). Canberra: Pacific Linguistics.

Beavers, John. 2011. On affectedness. Natural Language and Linguistic Theory 29(2). 335-370.

Bickel, Balthasar. 2010. Grammatical relations typology. In Jae Jung Song (ed.), The Oxford handbook of language typology, 399-444. Oxford: Oxford University Press.

Bohnemeyer, Jürgen, Melissa Bowerman \& Penelope Brown. 2001. Cut and break clips. In Stephen C. Levinson \& N.J. Enfield (eds.), Manual for the field season 2001, 90-96. Nijmegen: Max Planck Institute for Psycholinguistics.

Bossong, Georg. 1991. Differential object marking in Romance and beyond. In Dieter Wanner \& Douglas A. Kibbee (eds.), New analyses in Romance linguistics, selected papers from the XVIII linguistic symposium on Romance languages 1988, 143-170. Amsterdam: Benjamins.

Dixon, R. M. W. 1994. Ergativity. Cambridge: Cambridge University Press.

Donohue, Mark \& Søren Wichmann (eds.). 2008. The typology of semantic alignment. Oxford: Oxford University Press.

Evans, Nicholas, Stephen C. Levinson, N.J. Enfield, Alice Gaby \& Asifa Majid. 2004. Reciprocal constructions and situation type. In Asifa Majid (ed.), Field manual volume 9, 25-30. Nijmegen: Max Planck Institute for Psycholinguistics.

Fedden, Sebastian, Dunstan Brown, Greville Corbett \& Matthew Baerman. n.d. Surrey video stimuli for pronominal marking. Surrey Morphology Group.

Foley, William A. \& Robert Van Valin. 1984. Functional syntax and universal grammar. Cambridge: Cambridge University Press.

Givón, Talmy. 1985. Ergative morphology and transitivity gradients in Newari. In Frans Plank (ed.), Relational typology, 89-107. Berlin: Mouton.

Haan, Johnson W. 2001. The grammar of Adang: A Papuan language spoken on the island of Alor, East Nusa Tenggara, Indonesia. Sydney: University of Sydney PhD dissertation.

Holton, Gary. 2010. Person-marking, verb classes, and the notion of grammatical alignment in Western Pantar (Lamma). In Michael Ewing \& Marian Klamer (eds.), Typological and areal analyses: contributions from east Nusantara, 97-117. Canberra: Pacific Linguistics.

Holton, Gary, Marian Klamer, František Kratochvíl, Laura C. Robinson, and Antoinette Schapper. To appear. The historical relation of the Papuan languages of Alor and Pantar. Oceanic Linguistics.

Klamer, Marian. 2008. The semantics of semantic alignment in eastern Indonesia. In Mark Donohue \& Søren Wichmann (eds.), The typology of semantic alignment, 221-251. Oxford: Oxford University Press. 
Klamer, Marian. 2010. A grammar of Teiwa. Berlin: De Gruyter Mouton.

Klamer, Marian \& František Kratochvíl. 2006. The role of animacy in Teiwa and Abui (Papuan). In Proceedings of BLS 32. Berkeley: Berkeley Linguistic Society.

Kratochvíl, František. 2007. A grammar of Abui. Utrecht: LOT (PhD dissertation).

Kratochvíl, František. 2011. Transitivity in Abui. Studies in Language 35(3). 589636.

Kratochvíl, František. to appear. Differential case marking in Abui.

Malchukov, Andrej. 2005. Case pattern splits, verb types and construction competition. In Mengistu Amberber \& Helen de Hoop (eds.), Competition and variation in natural languages: The case for case, 73-117. Amsterdam: Elsevier.

Mithun, Marianne. 1991. Active/agentive case marking and its motivations. Language 67(3). 510-546.

Mithun, Marianne. 2008. The emergence of agentive systems in core argument marking. In Mark Donohue \& Søren Wichmann (eds.), The typology of semantic alignment, 297-333. Oxford: Oxford University Press.

Mohanan, Tara. 1990. Arguments in Hindi. Stanford, CA: Stanford University PhD dissertation.

Rude, Noel. 1983. Ergativity and the active-stative typology in Loma. Studies in African Linguistics 14(3). 265-283.

Siewierska, Anna. 2011. Verbal person marking. In Matthew S. Dryer \& Martin Haspelmath (eds.), The World Atlas of Language Structures Online, chapter 102. Munich: Max Planck Digital Library. Available online at http://wals.info/chapter/1. Accessed on 2011-09-19.

Tsunoda, Tasaku. 1985. Remarks on transitivity. Journal of Linguistics 21(2). 385396.

von Heusinger, Klaus \& Georg Kaiser. 2011. Affectedness and differential object marking in Spanish. Morphology 21(1). 1-25.

von Heusinger, Klaus \& Georg Kaiser. 2005. The evolution of differential object marking in Spanish. In Klaus von Heusinger \& Georg Kaiser (eds.), Proceedings of the workshop 'Specificity and the evolution/emergence of nominal determination systems in Romance', 33-70. Konstanz: Universität Konstanz. 